\title{
LA TEORÍA DEL DERECHO NATURAL EN EL TIEMPO POSMODERNO*
}

\author{
Carlos I. Massini Correas \\ Universidad de Mendoza (Argentina)
}

\begin{abstract}
otivados por uno de los sub-temas del presente Congreso: «Justicia y Derecho Natural», al planteo y discusión de la problemática del Derecho Natural desde la perspectiva de la filosofía del derecho, vamos a abordar sintéticamente el tema de las posibilidades del iusnaturalismo en los -tiempos posmodernos y, en especial, el del cometido de la teoría del derecho natural en ese contexto. En otras palabras, de lo que se tratará aquí es de intentar una respuesta a estas preguntas: i) ¿en qué situación ha quedado la teoría del derecho una vez colapsado el paradigma jurídico moderno y aparecidos los llamados "posmodernismos», que han ensayado la aplicación al derecho de nuevos paradigmas?; ii) ¿frente a esa situación, tiene alguna tarea relevante que cumplir la teoría -o teorías- del derecho natural?; y iii) en caso afirmativo: ¿en qué consiste fundamentalmente esa nueva tarea del iusnaturalismo en los tiempos posmodernos?
\end{abstract}

\section{Las notas de la modernidad}

Para comprender la situación actual de la teoría del derecho, resulta conveniente, como en casi todas las materias, hacer un poco de historia. En este caso vamos a remontarnos sólo hasta la edad moderna, ya que, como dice bien Daniel Innerarity, «la filosofía contemporánea se ha convertido en una reflexión sobre la modernidad» ${ }^{1}$. Esquematizando mucho por elementales razones de brevedad, podemos afirmar que es posible distinguir en la filosofía moderna tres rasgos centrales, en tomo a los cuales giran las ideas

* Debo agradecer aquí expresamente a Miguel Verstraete, Ricardo Crespo, Daniel Gamarra y Jorge Martínez Barrera, quienes leyeron el original de este trabajo y sugirieron valiosas y oportunas correcciones.

${ }^{1}$ Innerarity, D., Dialéctica de la modernidad, Madrid, Rialp, 1990, p. 13. Vide. asimismo: Llano, A., «Claves filosóficas del actual debate cultural», en Humanitas, $\mathrm{N}^{\circ}$ 4, Santiago de Chile, 1996, pp. 532-544. 
e ideales de esa etapa del pensamiento; estos rasgos son, esbozados esquemáticamente, los siguientes:

a) Pérdida de la noción teleológica de naturaleza: en este sentido, la noción clásica del mundo como naturaleza dotada de un sentido intrínseco entró en crisis fundamentalmente a partir de la captación excluyente de la realidad por parte de las modernas ciencias naturales, las que, por un lado, la concibieron como una mera materia objetivable, mensurable y cuantificable y, por otro, como el objeto de un dominio, por parte del hombre, progresivo y manipulador. "Con el nacimiento de la ciencia moderna -escribe Robert Spaemann- se produjo el abandono de la teleología. Este abandono no fue forzado por el fenómeno; detrás de él se escondía un poderoso interés. El fenómeno se opone incluso a una interpretación no teleológica. Por eso fuerza un equivalente provisional. Uno de estos equivalentes es la doctrina de los dos mundos en sus distintas formas: reino de las causas y reino de los fines, ser y deber, hechos y valores. La misma teoría de los valores es uno de estos equivalentes. Hechos desprovistos de valor y reino de valores opuesto a estos hechos es el producto de la desintegración de la entelequia (la naturaleza en cuanto fin; CIMC) precedente» ${ }^{2}$.

Esta desintegración de la naturaleza como entelequia, no fue sino una parte coherente del proceso que Max Weber llamó de «desencantamiento del mundo», y por el cual éste pasó de ser un «kosmos» ordenado en sí mismo, a desempeñar el papel de una mera res extensa, apta sólo para los cálculos y mediciones de un conocimiento reducido deliberadamente a ciencia físico-matemática y ordenado intrínsecamente a su ulterior utilización técnica. Por supuesto que del mundo, así concebido, no puede extraerse significación ni directiva alguna para la conducta humana, la que queda librada a la autonomía de la razón entendida como constructora de sus objetos. Entra en crisis, por lo tanto, la noción clásica de «ley natural», en el sentido de una normatividad del obrar humano que podía ser descubierta, en sus líneas generales, a través de una interpretación de la realidad natural ${ }^{3}$.

b) Aparición de la concepción moderna del sujeto: a ese mundo mudo y sin sentido intrínseco se le opondrá en la edad moderna un sujeto configurador de sus objetos de conocimiento y de voluntad. Para este sujeto, «conocer es poder» (Bacon) y se encuentra lanzado a la búsqueda de una ciencia que lo haga «dueño y señor de la naturaleza» (Descartes). Escribe a es-

${ }^{2}$ Spaemann, R., «La actualidad del derecho natural», en Crítica de las utopías políticas, Pamplona, EUNSA, 1980, pp. 324-25. Sobre las ideas de Spaemann a este respecto, vide. el libro de Ana Marta González, Naturaleza y dignidad. Un estudio desde Robert Spaemann. Pamplona, EUNSA, 1996. 1968.

${ }^{3}$ Vide. Villey, M., La formation de la pensée juridique moderne. Paris, Montchrestien, 
te respecto Gómez Robledo, que «en un mundo, en efecto, que se ha reducido a materia y a movimiento, a relaciones físico-matemáticas conociendo las cuales puede el hombre, dentro de ciertos límites, actuar y dominarlo, la acción tiene un valor incomparablemente mayor que la contemplación. Lo tiene porque el hombre es, a su vez, de mucho mayor dignidad que ese mundo, y a quien es superior corresponde más bien actuar en lo que es inferior, que limitarse a adoptar la actitud pasiva del espectador $\rangle^{4}$. Este sujeto es, entonces, el donador del sentido de la realidad a través de una función constructiva, ya no contemplativa, de la conciencia razonante y de la voluntad. Y esta conciencia no puede ser sino constructiva, en razón de que, al haber dejado de ser receptiva, sus contenidos pueden obtenerse solamente a través de un proceso metódicamente controlado de elaboración o construcción. Como consecuencia, todo lo existente cobrará sentido con referencia al sujeto, y en especial los contenidos de la eticidad, sea ésta personal o social.

e) Inmanentización del pensamiento: este pensamiento centrado en el sujeto tiende progresivamente a transformarse en inmanente, tanto en el sentido de la inmanencia metafísica: negación de todo lo trascendente al mundo, como de la inmanencia noética: negación de todo lo que no sea contenido de la conciencia. Rafael Alvira ha escrito, con gran precisión, que «es la negación, explícita o implícita, de la trascendencia, y la aparición de la primacía de la conciencia, lo que caracteriza, a mi juicio, a esta modernidad par excellence» ${ }^{5}$. Como consecuencia de esta negación, el pensamiento moderno se «emancipa» de toda sujeción posible; ya sea «por arriba», al liberarse del control de la revelación y de la teología, ya sea «por debajo», al liberarse de los inevitables límites que ponen las estructuras de la realidad a un pensamiento contemplativo y receptivo. Este movimiento hacia una cada vez mayor inmanencia, explica el tránsito, en el campo de las ideas y de las vivencias religiosas, del teísmo al deísmo y, finalmente al ateísmo ${ }^{6}$. Por supuesto que, dentro de este esquema, resulta absolutamente impensable la noción tomasiana de ley natural como «participación de la ley eterna en la criatura racional» ${ }^{7} \mathrm{y}$, como consecuencia, el Derecho Natural Moderno centrará sus esfuerzos en la construcción racional de un completo y metódicamente riguroso sistema jurídico ${ }^{8}$.

\footnotetext{
${ }^{4}$ Gómez Robledo, A., Ensayo sobre las virtudes intelectuales, México, FCE, 1986, p. 145. Vide. «L'etica teologica e le istanze della posmodernità», en AA.VV., Prospettive etiche nella posmodernità, Milano, San Paolo, 1994, pp. 54 ss.

${ }^{5}$ Alvira, R., Reivindicación de la voluntad, Pamplona EUNSA, 1988, p. 228.

${ }^{6}$ Vide. Fazio, M. y Gamarra, D., Introduzione alla storia della filosofia moderna, Roma, Apollinare Studi, 1994.

${ }^{7}$ Tomás de Aquino, Summa Theologiae, I-II, q. 91. a. 2.

${ }^{8}$ Vide. Massini Correas, C.I., La desintegración del pensar jurídico clásico en la Edad Moderna, Buenos Aires, Abeledo Perrot, 1980. Todas estas notas adquieren su formulación pa-
} 


\section{La modernidad eticojurídica}

Si las trasladamos ahora al ámbito del derecho, estas notas propias de la modernidad van a transformarse en otros tantos caracteres del pensamiento jurídico moderno; expuestos sucintamente, éstos son los siguientes:

a) Pérdida de la noción clásica de ley natural: al desaparecer la concepción clásica de naturaleza-entelequia, capaz de ser fuente de sentido jurídico y raíz de contenidos normativos con relativa independencia del sujeto pensante, ese sentido y esa raíz se colocan necesariamente en ese sujeto, quien fabrica normas y principios prácticos a partir de postulados de su misma razón. «Con la parcial excepción de Grocio -escribe Knud Haakonsen- estos escritores modernos (Hobbes, Pufendorf, Locke, etc.; CIMC) sostenían que no hay ningún significado moral o político inherente en la estructura de las cosas. Todo significado o valor es querido o construido e impuesto sobre un mundo natural que en sí mismo es amoral y apolítico» ${ }^{9}$. Este modo de pensar se pone especialmente en evidencia en las ideas de David Hume, para quien las nociones de justicia, propiedad, derecho, etc. son meramente «artificiales», creaciones voluntarias del hombre por razones de utilidad común $^{10}$. Desde esta perspectiva, el espacio antes ocupado por la ley natural, será llenado por un «derecho racional» construido deductivamente por el sujeto a partir de postulados de su misma razón; ésta y no otra es la fuente de los modernos sistemas de «Derecho Natural», que precedieron a la codificación, al constitucionalismo racional-normativo y al «sistemismo jurídico» del siglo XX.

b) Aparición de la moderna noción de derechos humanos: de modo coherente con la exaltación de un sujeto dador de sentido y dotado de una autonomía «fuerte» o absoluta, aparece la moderna noción de derechos humanos, que los concibe como prerrogativas inherentes al sujeto, previas a su vida social y sin fundamento trascendente alguno. La única justificación racional que puede darse en esta perspectiva a los derechos humanos, radica en la «santidad» (Kant) que corresponde a la persona humana en virtud de su autonomía y de su racionalidad. «La modernidad de las declaraciones de

radigmática en el pensamiento de I. Kant: «Kant -escribe Habermas- expresa el mundo moderno en un edificio de ideas»; Habermas, J., El discurso filosófico de la modernidad, Buenos Aires, Taurus, 1989 , p. 32. Tanto es así, que la gran mayoría de los intentos contemporáneos de reividicar y revalorizar el pensamiento de la modernidad se remiten, directa o indirectamente, al mismo Kant; vide. Rosen, A.D.; Kant's Theory of Justice, Ithaca-London, Cornell U.P, 1993.

${ }^{9}$ Haakonsen, K., Natural Law and Moral Philosophy. From Grotius to the Scottish Enlightenment, New York, Cambridge U.P., 1996, p. 102.

${ }^{10}$ Vide. Hume, D., Treatise of Human Nature, London, Penguin Classics, 1985, pp. $529-552$. 
derechos del hombre de finales del siglo XVIII -escribe Blandine Barret-Kriegel- está necesariamente vinculada con la filosofía de la conciencia y la teoría del sujeto. Más aún, ellas son el testimonio de un acontecimiento irreversible en la historia de la filosofía: la transformación de la idea de naturaleza y el advenimiento del sujeto» ${ }^{11}$.

c) Fundamentación inmanente del derecho: otra cosa cambia finalmente en la edad moderna: la fundamentación del derecho y de los derechos ya no radica en la ley eterna de Dios, ni en la ley natural descubierta a partir de las estructuras de las cosas, sino pura y simplemente, ya sea en la razón del sujeto constructor: Derecho Natural Moderno, ya sea en los simples mandatos del soberano: Imperativismo, de Hobbes a Kelsen, pasando por Bentham y Austin ${ }^{12}$. En todos los casos, es siempre el sujeto humano el que da origen integral a las normas de la convivencia, ya sea porque construye un sistema jurídico racional, ya sea porque instituye, como a un artificio, a la autoridad que impera las normas. $Y$ es en esta ruptura normativa de la modernidad con la trascendencia ontológica y noética donde se encuentra la raíz auténtica del positivismo jurídico, el que se hace epistémicamente posible sólo a partir de la más completa inmanentización de los fundamentos de los órdenes jurídico y moral ${ }^{13}$.

\section{La crítica posmoderna}

La concepción moderna del derecho que hemos sintetizado y esquematizado en el punto precedente, se constituyó en la corriente central de la teoría del derecho hasta bien entrado el siglo XX. Es cierto que ella fue objeto de persistentes embates por parte de los defensores de la concepción clásica del derecho, pero estos ataques no pudieron hacer peligrar su reinado, el que se mantuvo con altibajos prácticamente hasta la década de los 70 . A partir de este momento, una nueva corriente de ideas hizo su aparición en el escenario político de Occidente, centrándose en una crítica integral del proyecto moderno y recurriendo a Marx, Nietzsche, Freud y Heidegger como a sus mentores principales. Dentro de esta corriente, que reivindica para sí

${ }^{11}$ Barret-Kriegel, B., Les droits de l'homme et le droit naturel, Paris, PUF, 1989; sobre la problemática general del pensamiento jurídico moderno, esta autora afirma que en él «una cosa se ha perdido: la idea de una ley natural, en la que se acuerdan, juegan, se ven y regulan el hombre y el mundo. Otra cosa resulta, en contraposición, promovida: el orden de la naturaleza humana como arte, fabricación, convención, intelección» (p. 53).

${ }^{12}$ Sobre estos autores, vide. Kelly, J. M., A Short History of Western Legal Theory, Oxford, Clarendon Press, 1994, pp. 301 ss.

${ }^{13}$ Vide. Carpintero, E, Los inicios del positivismo jurídico en Centro Europa, Madrid, Actas, 1993; asimismo, vide. Goyard Fabre, S., Les fondements de l'ordre juridique, Paris, PUF, 1992, pp. 95 ss. 
el monopolio del pensamiento posmodemo y que tiene a sus principales representantes dentro del posestructuralismo francés, se han realizado también intentos de someter a crítica integral a la concepción moderna del derecho y de la eticidad en general ${ }^{14}$. Vamos a exponer sucintamente las líneas principales de esta crítica posmoderna, para hacer posible luego el estudio de los intentos de salida del punto muerto a que arriba esta crítica absoluta, meramente negativa y sin solución ${ }^{15}$; estas líneas críticas, coincidentes con las que hemos analizado al estudiar la modernidad, son las siguientes:

a) Crítica de la razón constructiva y sistemática: uno de los principales puntos de la crítica posmoderna al pensamiento de la modernidad, radica en la negación de las posibilidades sistematizadoras y constructivas de la realidad que habían sido atribuidas a la razón. «El contexto actual de la filosofía -escribe Innerarity- viene definido por la crítica del paradigma moderno de una razón totalizadora (...). La ruptura con la razón totalizadora supone -para Lyotard- el abandono de los grand récits, es decir, de las grandes narraciones, del discurso con pretensiones de universalidad, y el retorno de las petites histoires (...). Y ha perdido credibilidad la idea de un discurso, consenso, historia o progreso en singular: en su lugar aparece una pluralidad de ámbitos de discurso y narraciones» ${ }^{16}$. La razón constructiva, sistemática y universalista de la modernidad, atacada como «torturadora» y «encubridora» de la realidad, resulta sustituida en la perspectiva posmoderna por una «arqueología del saber» (Foucault), que desemboca finalmente en un irracionalismo anárquico, descontextualizado y anónimo.

En el ámbito de lo eticojurídico, esto significa ante todo una des-fundamentación del orden normativo: la razón moderna que lo justificaba racionalmente desaparece y la autoridad que imponía los imperativos -en el caso del imperativismo decimonónico- resulta sospechada como encubridora de dominación ${ }^{17}$. Como consecuencia, el derecho queda reducido a meras estructuras anónimas del lenguaje, que ocultan y canonizan estructuras de opresión o dominio; el derecho, escribe Kozieki, se reduce a «grafismos inventados por Occidente para sus producciones de regimentación social» ${ }^{18}$. Por supuesto que la fundamentación moderna del derecho, sea ésta racionalista o imperativista, no es sustituida por ninguna otra: simplemente el de-

${ }^{14}$ Sobre estos intentos, vide. Renaut, A. y Sosoe, L., Philosophie du Droit, Paris, PUF, 1993, pp. 41-68.

${ }^{15}$ Vide. Ballesteros, J., Posmodernidad: decadencia o resistencia, Madrid, Tecnos, 1989.

${ }^{16}$ Innerarity, D., o.c., pp. 114-115.

17 Sobre la «filosofía de la sospecha», vide. Genghini, N., Verità \& Consenso. La controversia sui fondamenti morali dell'ordine politico, Bologna, Ed. CSEO, 1989, pp. 12 y passim.

${ }^{18}$ Kozieki, E., «Discurso jurídico y discurso psicoanalítico», en AAVV., El discurso jurídico, Buenos Aires, Hachette. 1982, p. 30. 
recho pasa a carecer de fundamento; «el derecho -escribe Ewald- no puede sostenerse hoy en día sino en su propia positividad» ${ }^{19}$.

b) Pérdida de la noción de sujeto: el ataque a la noción moderna de sujeto es uno de los puntos centrales de la crítica posmoderna; Foucault la considera en Les mots et les choses un mero «invento del siglo XVIII» y los autores de esa corriente proponen la «liberación como sobrepasamiento del sujeto ${ }^{20}$, es decir, sustituirlo por estructuras anónimas e inconscientes, en las que ese sujeto se difumina hasta desaparecer. Escribe en este sentido Innerarity, que el poste structuralismo «sustituye el trascendentalismo de la conciencia por el del inconsciente, bajo la forma del discurso anónimo de las estructuras sociales, lingüísticas o simbólicas $\rangle^{21}$. Desde esta perspectiva, el sujeto ya no es más el dispensador de sentido de la realidad; y como, por otra parte, el sentido inherente de la naturaleza clásica no reaparece, no existe ya lugar donde escrutar el sentido del derecho: éste termina por carecer de sentido.

Esta pérdida del sujeto significa, en el campo jurídico, la desaparición de las nociones de derecho subjetivo y de derechos humanos, así como, en definitiva, de la noción misma de derecho. En efecto, el derecho -y por lo tanto los derechos- es una realidad existencialmente no autónoma, que necesita de un sujeto existencialmente autónomo para existir; si excluimos a ese sujeto, el derecho debe necesariamente desaparecer por carencia de una base óntica en la que inherir para poder ser. Es por ello que uno de los traductores de la posmodernidad en el ámbito jurídico, F. Ewald, concluye afirmando que «el derecho no existe» ${ }^{22}$ y Deleuze defiende que «contrariamente a lo que sostiene el discurso habitual, no hay ninguna necesidad de referirse al hombre para resistir a la dominación $\rangle^{23}$. La resistencia, por lo tanto, no es ya pensable en términos de derechos, en especial de derechos humanos, sino en el de relaciones de nudo poder: el mundo jurídico se ha disuelto entonces en una red de relaciones meramente fácticas y sin sentido deóntico.

c) Ausencia de fundamento de las realidades jurídicas: finalmente, los intentos modernos de fundamentación del derecho aparecen, en clave posmoderna, cuestionados en cuanto meros encubridores de dominación. Por ello, los procesos de fundamentación o justificación racional de lo jurídico

${ }^{19}$ Ewald, F., L'Etat providence, Paris, Grasset, 1986, p. 41.

${ }^{20}$ Vide. Renaut, A. y Sosoe, L., o.c., pp. 43 ss.; vide también: Amato, S., Il soggetto e il soggetto di diritto, Torino, Giappichelli, 1990, pp. 31 ss.

${ }^{21}$ Innerarity, D., o.c., p. 39.

${ }^{22}$ Ewald, F., o.c., p. 30.

${ }^{23}$ Deleuze, G., Foucault, Paris, Minuit, 1986, p. 98. 
resultan sustituidas por una «arqueología» o «genealogía» ${ }^{24}$ del derecho, que busca develar su origen encubierto en relaciones de mero poder. Foucault ha llevado a cabo este proceso arqueológico, respecto del derecho, en su libro «La verdad y las formas jurídicas»; allí escribe que «la función del análisis arqueológico sería, en primer lugar, descubrir las continuidades oscuras que hemos incorporado $\mathrm{y}$, en segundo lugar, partiendo del estudio de su formación, comprobar la utilidad que han tenido y que aún siguen teniendo; es decir, cómo actúan en la actual economía de nuestras condiciones de existencia. En tercer lugar, el análisis histórico-arqueológico permitiría además determinar a qué sistema de poder están ligadas estas bases o continuidades y, por consiguiente, cómo abordarlas $\rangle^{25}$. Por su parte, Deleuze concluye que «el derecho no es sino el estado de paz que es el resultado de una guerra ganada: es la misma guerra y la estrategia de esta guerra en acto $»^{26}$. Dicho en otras palabras, el derecho se reduce, en última instancia, a relaciones de nudo poder o de guerra, y la única tarea valiosa a su respecto es la «arqueológica», que permite descubrir la realidad originaria del derecho, desenmascarando los intentos justificatorios $\mathrm{y}$, en definitiva, «liberándonos del pasado» ${ }^{27}$. Por supuesto que tanto la realidad jurídica que se resume en relaciones de poder, como la resistencia a esas relaciones, también concebida como mera reacción fáctica o violenta, carecen de fundamento alguno -sea éste trascendente o inmanente- y tampoco lo necesitan; se sostienen por sí mismos en cuanto poder fáctico; por lo tanto corresponde desechar como espúreos, mistificadores o encubridores a todos los ensayos justificadores del derecho.

\section{Los intentos de refundamentación (I): el Neoiluminismo}

Ahora bien, es evidente que, no obstante sus aspectos críticos positivos, que no es éste el momento de detallar ${ }^{28}$, el nihilismo jurídico del mero poder y de la desfundamentación del derecho no puede satisfacer las exigencias mínimas del espíritu humano y, consecuentemente, de la convivencia humana social. Efectivamente, todo sistema jurídico requiere de modo necesario, para su existencia en cuanto tal, de los tres siguientes elementos: i) un criterio de fundamentación del derecho, o de la obligatoriedad de las normas jurídicas, ya que el mero factum de la fuerza no es suficiente para lo-

\footnotetext{
${ }^{24}$ Vide. MacIntyre, A., Tres versiones rivales de la ética. Enciclopedia, genealogía y tradición, trad. R. Rovira, Madrid, Rialp, 1992, pp. 61 ss.

${ }^{25}$ Foucault, M., La verdad y las formas jurídicas, trad. E. Lynch, Barcelona, Gedisa, 1984, p. 171.

${ }^{26}$ Deleuze, G., o.c., p. 38.

${ }^{27}$ Foucault, M., o.c., p. 172.

${ }^{28}$ Vide. Verstraete, M., Modernidad agónica, pro manuscripto, sobre todo, cap. V.
} 
grar la vigencia del derecho; aún los autores más crudamente positivistas ${ }^{29}$ reconocen que para que el derecho tenga una mínima vigencia es preciso algún tipo de convencimiento ético en quienes han de respetarlo; ii) una instancia crítica de apelación valorativa, situada más allá del mero poder, y ante la cual los dictámenes de ese poder puedan ser evaluados como justos o injustos; dice a este respecto Spaemann que, de hecho, «los hombres distinguen acciones justas e injustas. Y el criterio último de esta distinción no es la adecuación de las acciones a las leyes positivas existentes, pues estos mismos hombres distinguen también leyes justas e injustas, sentencias justas e injustas» ${ }^{30}$; y iii) un sub-jectum existencialmente autónomo en el que inhieran o tengan su existencia el derecho y los derechos-, como ya lo hemos dicho -y es por otra parte evidente- el derecho en todas sus dimensiones tiene una existencia no autónoma, que Aristóteles llamaría «accidental» y, por lo tanto, necesita de un ente sustantivo que sostenga su existencia; sin esta sustancia, no puede siquiera pensarse el derecho. Ahora bien, los pensadores posmodernos no sólo no proporcionan a la teoría del derecho estos tres elementos, sino que los niegan explícitamente, dando lugar a otras tantas aporías, irresolubles en los marcos de ese mismo pensamiento.

La consecuencia de estas aporías a que conduce inexorablemente el pensamiento de la posmodemidad, sobre todo en la versión del posestructuralismo arqueológico, ha sido la aparición de varios y diversos intentos de solución o de escape a esas aporías; dicho de otro modo, se han ensayado, por parte de una larga serie de pensadores contemporáneos, varias salidas superadoras de estas dificultades y capaces de refundamentar de algún modo al derecho y a los principios de la organización política y reencontrar, por otra parte, al sujeto perdido en la posmodernidad, así como a la necesaria instancia suprapositiva de apelación ética. De entre estos intentos contemporáneos, vamos a detenemos especialmente sólo en dos, los que nos parecen más relevantes en este punto ${ }^{31}$, y luego de referirnos brevemente a ellos, esbozaremos una necesaria conclusión programática.

El primero de estos intentos de refundamentación del derecho y la política está dado por lo que puede llamarse «neo-iluminismo» ${ }^{32} \mathrm{o}$ «tardomodernidad»: para esta corriente, el proyecto moderno es un «proyecto inaca-

\footnotetext{
${ }^{29}$ Vide. Raz, J., Ethics in the Public Domain, Oxford, Clarendon Press, 1994, p. 340 y passim.

${ }^{30}$ Spaemann, R., o.c., p. 315.

31 También podrían efectuarse aquí algunas consideraciones sobre los llamados «comunitaristas» anglosajones, pero las omitiremos por razones de espacio; para una visión de conjunto de este movimiento, vide: Naval, C., Educar ciudadanos. La polémica liberal-comunitarista en educación, Pamplona, EUNSA, 1995, pp. 59-126.
}

${ }^{32}$ Vide. sobre este tema: Possenti, V., Oltre l'illuminismo, Milano, Paoline, 1992. 
bado» (Habermas), cuyos valores es necesario rescatar por intermedio, ya sea de un retorno a Kant (Rawls, Renaut), a los contractualistas liberales (Nozick, Buchanan) o a la tradición utilitarista (Lyons, Scanlon). A través de este retorno a la tradición moderna, se intenta reivindicar las nociones de sujeto moral $^{33}$, de ciertos principios de justicia no-positivos y de una fundamentación racional-constructiva de esos principios.

De este programa, corresponde destacar principalmente la idea de un procedimiento de fundamentación de los principios eticojurídicos de carácter constructivo-procedimental, en lo que termina siendo la acentuación de uno de los caracteres centrales del pensamiento de la modernidad; esta idea adquiere un carácter paradigmático en el pensamiento de John Rawls; para este autor norteamericano, «el constructivismo kantiano sostiene que la objetividad moral ha de entenderse en términos de un punto de vista social adecuadamente construido y que todos puedan aceptar. Fuera del procedimiento de construir los principios de justicia, no hay hechos morales. El que ciertos hechos hayan de ser reconocidos como razones de lo recto y de la justicia, o en qué medida hayan de contar, es algo que sólo se puede determinar desde dentro del procedimiento de construcción, esto es, a partir de los compromisos adoptados por agentes racionales de construcción, cuando se encuentran debidamente representados como personas libres e iguales $\gg{ }^{34}$.

Esta pretensión de reconstruir procedimentalmente la objetividad ética, no es sino una consecuencia tardía del abandono moderno de la ley natural: perdida la objetividad entitativa, fuerte, del pensamiento clásico, no puede sino desembocarse, ya sea en la pérdida absoluta de toda objetividad, como en el caso de los posmodemos, ya sea en el intento de reconstruir esa objetividad de modo formal-procedimental-consensual. En este último caso, se termina en una ética «basada sobre una argumentación puramente retórica, es decir, sobre una serie de argumentos ad hominem, mensurada sobre las personas con las que se ha de construir» ${ }^{35}$. Pero esta ética construida procedimentalmente, sin referencia alguna a los datos de la experiencia moral ${ }^{36}$ a principios autoevidentes de carácter material o contenutístico, desemboca a su vez en dos aporías fundamentales que la desautorizan en cuanto alternativa válida del nihilismo posmoderno:

${ }^{33}$ Vide. Sandel, M., Liberalism and the Limits of Justice, Cambridge, Cambridge U.P., 1992, pp. 15-65.

${ }^{34}$ Rawls, J., «El constructivismo kantiano en la teoría moral», en Justicia como equidad, trad. M.A. Rodilla, Madrid, Tecnos, 1986, p. 140.

${ }^{35}$ Vattimo, G., La filosofía al presente, Milano, Garzanti, 1990, p. 86.

${ }^{36}$ Acerca de la noción de experiencia moral, vide.: Privitera, S., Dall'esperienza alla morale, Palermo, Ed. OFTES, 1985. 
a) La primera de ellas es que nos encontramos frente a una fundamentación «débil» de una normatividad constitutivamente fuerte como es la jurídica; en efecto, la obligatoriedad o exigibilidad de las normas o poderes jurídicos -al menos de los que aparecen como centrales en todo derecho- no puede ser pensada sino como exigiendo un respeto incondicionado, absoluto o sin excepción: una obligación que pudiera ser «sobrepasada» o dejada de lado por consideraciones de utilidad personal o colectiva, conveniencia subjetiva o fastidio personal, no podría ser considerada rigurosamente como jurídica. La necesidad deóntica es uno de los caracteres imprescindibles de la juridicidad, al menos en su núcleo central y en su significación más propia, y es evidente que la fundamentación procedimental -constructiva no alcanza la «fuerza» necesaria como para justificarla racionalmente.

b) La segunda de las aporías del constructivismo-procedimental-consensual, reside en lo que hemos dado en llamar la «falacia procedimentalista», que consiste en la pretensión de obtener principios eticojurídicos contenutísticos del mero procedimiento argumentativo de la razón práctica constructiva. Arthur Kaufmann ha puesto en evidencia, en uno de sus últimos trabajos ${ }^{37}$, cómo resulta imposible, sin incluir en el razonamiento contenidos que se deban en alguna medida a la experiencia, extraer conclusiones materiales o contenutísticas. Esto es, por otra parte, una exigencia ineludible de la lógica, que impide que en las conclusiones de un razonamiento aparezca algo no contenido de algún modo en las premisas antecedentes. De este modo, si lo que se pone en las premisas del razonamiento procedimentalista son meras construcciones formales (situaciones originales, velos de ignorancia, liberaciones de dominio, etc.), lo que resultará en la conclusión, por más vueltas que se le dé a los argumentos, no será sino un conjunto de proposiciones sin contenido material y referidas a las meras formas del razonamiento.

\section{Los intentos de refundamentación (II): el Neoiusnaturalismo}

Pero es bien claro que no es esta eticidad débil y meramente formal lo que puede superar las aporías planteadas tan agudamente por la posmodernidad jurídica; esta salida «neoiluminista» no es en realidad una salida, sino más bien una recaída agravada en las perplejidades y dificultades insalvables del pensamiento moderno. Por ello, es preciso dirigir la mirada hacia otro de los intentos de superación del nihilismo irracionalista, que a la vez lo es también del racionalismo constructivista y del positivismo propios de la mentalidad moderna: se trata de la más reciente renovación del pen-

${ }^{37}$ Vide. Kaufmann, A., La filosofía del derecho en la posmodernidad, trad. L. Villar Borda, Bogotá, Temis, 1992, pp. 47 ss. 
samiento iusnaturalista. En esta renovación, lo que se intenta ante todo es la reformulación de un objetivismo eticojurídico que tenga como base a la verdad, para lo que resulta imprescindible abrirse nuevamente a la naturaleza de las cosas humanas; esta apertura, sobre todo en el ámbito de sociedades multiculturales, deberá hacerse a través de un diálogo lo más amplio posible, pero habrá de tratarse de un «diálogo veritativo» ${ }^{38}$, estructurado sobre el supuesto de la posibilidad de alcanzar la verdad en el ámbito de la praxis humana. Esta verdad, por otra parte, no podrá alcanzarse sin un necesario recurso a la experiencia, sensible y espiritual, de las realidades propia y específicamente humanas.

Sólo sobre esta base será posible, en segundo lugar, alcanzar una fundamentación «fuerte» del derecho y de las instituciones políticas, una justificación racional de la regulación de la praxis humana que alcance el grado de inexcepcionabilidad que esa regulación requiere. Y para ello, será también necesario arraigar la realidad jurídica en un sujeto existencialmente autónomo que, a raíz de su racionalidad y su libertad, habrá de revestir el carácter de persona; persona que no se confundirá con el sujeto autosuficiente, constructor y único dador de sentido propio del pensamiento moderno, sino que se tratará de una sustancia racional constitutivamente abierta a la «coexistencia ontológica» (Cotta) con sus semejantes y ordenada a una perfección por la que se participa de un bien humano común.

Para la realización de esta tarea, será más que conveniente recurrir a la milenaria tradición de la doctrina de la ley natural; pero es indudable que, hoy en día, no basta con remitirse a los aportes de una tradición para hacer nuevamente aceptable la idea de la existencia de algo intrínsecamente justo: una nueva época requiere una nueva versión del derecho natural. Esto no significa sostener que deba tratarse de una versión completamente nueva, sino que ha de formularse a partir de los nuevos datos aportados por la actual experiencia de la vida social: por ejemplo, de las exigencias que se siguen de la actual crisis ecológica o de los planteamientos morales y jurídicos engendrados por la biología y la medicina contemporáneas. Y no sólo las nuevas experiencias habrán de ser tenidas en cuenta, sino también las más recientes aportaciones efectuadas en el campo de la filosofía y de la metodología, tales como la hermenéutica, la contemporánea metateoría de la ciencia y la filosofía analítica, convenientemente criticadas en sus reduccionismos, sus contradicciones y sus consecuencias indeseadas.

Por supuesto que esta tarea no es de las más fáciles; es mucho más cómodo remitirse dogmáticamente a textos venerables, interpretados según

${ }^{38}$ Chalmeta Olaso, G., Ética especial. El orden ideal de la vida buena, Pamplona, EUNSA, 1996, p. 202. 
claves hermenéuticas también venerables. El problema es que la versión del derecho natural que de allí resulta es poco comprensible -sino incomprensible- para los hombres de hoy. Y resultará entonces que esas doctrinas de derecho natural, mantenidas inconmovibles e inmodificables a lo largo de los siglos, no podrán cumplir la función crítica y de justificación racional que estos tiempos -como todos los tiempos- requieren de ellas. Es preferible, por lo tanto, correr el riesgo de repensar -siempre con la ayuda de la tradición iusnaturalista- los problemas que la vida social contemporánea, y en especial la jurídica, plantean agudamente al espíritu humano y resolverlos desde una perspectiva dialógica pero veritativa, plural pero no relativista, racional pero no sistemista, universalista pero abierta a la diversidad de las concreciones prudenciales de los principios de derecho natural. Se podrá alegar que esta tarea es ardua, compleja y riesgosa, pero también es verdad que no existe ni ha existido aventura humana que no revista esos caracteres. Y ésta, en especial, merece la pena ser asumida con decisión y grandeza de espíritu.

Finalmente, y antes de esbozar las correspondientes conclusiones, resumiremos esquemáticamente en un cuadro lo sostenido en los desarrollos realizados hasta ahora; el cuadro es el siguiente:

\begin{tabular}{|c|c|c|c|}
\hline $\begin{array}{c}\text { PENSAMIENTO } \\
\text { MODERNO }\end{array}$ & $\begin{array}{c}\text { FILOSOFÍA } \\
\text { JURÍDICA } \\
\text { MODERNA }\end{array}$ & $\begin{array}{c}\text { REACCIÓN } \\
\text { MODERNA }\end{array}$ & $\begin{array}{c}\text { INTENTOS DE } \\
\text { SUPERACIÓN }\end{array}$ \\
\hline $\begin{array}{c}\text { Pérdida de la noción } \\
\text { teleológica-normativ } \\
\text { a de naturaleza }\end{array}$ & $\begin{array}{c}\text { Pérdida de la noción } \\
\text { de «ley natural»- } \\
\text { Razón constructiva }\end{array}$ & $\begin{array}{c}\text { Crítica de la razón } \\
\text { sistemática } \\
\text { («grandes relatos») }\end{array}$ & $\begin{array}{c}\text { Neo-Iluminismo } \\
\text { procedimental- }\end{array}$ \\
\hline $\begin{array}{c}\text { Sujeto configurador } \\
\text { y dador de sentido de } \\
\text { sus objetos }\end{array}$ & $\begin{array}{c}\text { Aparición de la } \\
\text { moderna noción de } \\
\text { «derechos humanos» }\end{array}$ & $\begin{array}{c}\text { Crítica de la noción } \\
\text { de sujeto: estructuras } \\
\text { anónimas } \\
\text { inconscientes }\end{array}$ & consensual \\
\hline $\begin{array}{c}\text { Inmanentización } \\
\text { progresiva del } \\
\text { pensamiento y la } \\
\text { vida }\end{array}$ & $\begin{array}{c}\text { Fundamentación } \\
\text { inmanente del } \\
\text { derecho: racional- } \\
\text { imperativista }\end{array}$ & $\begin{array}{c}\text { Crítica de la } \\
\text { fundamentación } \\
\text { moderna del } \\
\text { derecho: sólo } \\
\text { arqueología del } \\
\text { saber- poder }\end{array}$ & $\begin{array}{c}\text { Renacimiento de las } \\
\text { teorías }\end{array}$ \\
iusnaturalistas \\
\hline
\end{tabular}

\section{Conclusiones}

De todos los desarrollos realizados, es posible extraer dos conclusiones principales para la problemática que nos ocupa, que resumiremos sucintamente del siguiente modo:

a) La teoría del derecho natural se encuentra, en los tiempos posmodernos, en una situación paradojal: por una parte, aparece como la necesaria sa- 
lida del atomismo nihilista y des-fundamentador del crepúsculo de la modernidad pero, por otra, se encuentra con graves dificultades de formulación y comunicación al hombre contemporáneo. En efecto, el hombre de nuestros días no comparte las certezas e imágenes que sí compartían quienes formularon antes de la edad moderna las doctrinas clásicas del derecho natural; dicho de otro modo, ya no es posible dar por sentado toda una serie de presupuestos nocionales: la concepción teleológica de la naturaleza, el sujeto como sustancia racional, el carácter trascendente del fundamento de la eticidad, etc. Por lo tanto, el intento de re-fundamentar el derecho a partir de las estructuras de la realidad tiene que vérselas hoy en día con numerosos desafíos, el primero de los cuales es el de iniciar esta tarea desde mucho más «atrás» -o mucho más «profundo»- y con muchos menos supuestos de lo que lo hicieran la mayoría de las formulaciones anteriores, inclusive algunas de bien entrado este siglo;

b) A pesar de estas dificultades de constitución y formulación, la teoría del derecho natural tiene algunas funciones irreemplazables que cumplir en este tiempo de postrimerías y ocaso de la modernidad ${ }^{39}$. Estas funciones son, ante todo, la de procurar la necesaria fundamentación «fuerte» de las realidades jurídicas, es decir, la de suministrar una justificación racional de su obligatoriedad y exigibilidad, de tal modo que resulte proporcionada al carácter inexcusable o absoluto -en sentido deóntico- de los imperativos, deberes y potestades jurídicas. Y en segundo lugar, pero en rigor de mayor importancia, es función inexcusable del derecho natural afirmar y asegurar la indisponibilidad del derecho; «en contra de la doctrina del positivismo legalista -escribe Günter Ellscheid- según la cual corresponde al Estado (y a los poderes humanos en general; CIMC) la disponibilidad sobre el derecho, el derecho natural pretende impedir (real o, al menos, normativamente) la posibilidad de que la legislación manipule al derecho. La idea de la indisponibilidad del derecho -concluye- siempre se ha considerado inherente a la idea de derecho natural, pues la naturaleza se ha entendido invariablemente como lo no establecido por la praxis

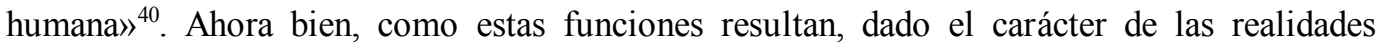
jurídicas, absolutamente necesarias, se vuelve también necesario abordar la tarea de reformulación de la teoría del derecho natural; esta tarea habrá de realizarse

${ }^{39}$ En este punto cabe recordar el valioso libro de Romano Guardini, El fin de los tiempos modernos, Buenos Aires, Sur, 1958 (el original alemán es de 1950), donde se plantea el problema del ocaso de la modernidad varios años antes de la aparición de la literatura «posmoderna».

${ }^{40}$ Ellscheid, G., «El problema del derecho natural. Una orientación sistemática», en AAVV., El pensamiento jurídico contemporáneo, ed. Gregorio Robles, Barcelona, Debate. 1992, p. 149. 
encarando y superando las dificultades que nuestro tiempo le plantea, pero sin amedrentarse o defeccionar ante la complejidad y multiplicidad de esas dificultades. Ellas han de ser, antes que obstáculos, nuevos desafíos a las inteligencias abiertas y comprometidas con la defensa del núcleo de humanidad que no puede faltar jamás en el derecho. 